and writer on optics, and Chapter 4, which ho contributes, is an outstandingly lucid and comprehensive manual on optical design. Within 130 pages, he clearly distinguishes between the three different types of optical instrument and lists their design parameters, and then describes in detail how the parameters may be determined for particular optical systems and how systems with given parameters may be designed from available light sources, optical materials and detectors. The chapter concludes with an extensive list of references to which the interested student may refer for additional study.

Two important but somewhat neglected topics are considered in Chapters 7 and 8 . These are the reliability of instruments and intrinsic safety. Finally, since an instrument is a piece of equipment to be used, the concluding remarks in the brief six pages of Chapter 9 on integrated design are valuable because they serve to remind the designer that instruments should be such as the user will like to handle and which will give him the information he requires in the most easily assimilated manner.

The Association continues to receive a large number of enquiries from home and overseas, and the Enquiry Service has been dealing with an average of 400-450 a month. A new leaflet directing attention to the service is being prepared for distribution to members. The card index system used to answer enquiries has been brought up to date. The Publicity Committee has been concerned with the improvement of Press relations for the greater dissemination of information about the instrument industry, and arrangements have been made in conjunction with the Central Office of Information to commission a series of articles on new developments and applications in instrumentation. The articles will be offered in the language of the country to technical journals overseas and also to selected journals in the United Kingdom. Mrs. H. Conway was appointed Press relations officer in July 1962.

S. Weintroub

\title{
THE NEW YORK ACADEMY OF SCIENCES
}

$\mathrm{T}$ THE 145th annual meeting of the New York Academy of Sciences was held on December 5,1962 , at 2 East 63 Street, New York. During the year ending October 31, 1962, considerable progress was made in the recovery of the Academy's financial status, both for improvement of its operating budget and for strengthening its investments. The increase in income permitted an extension of the budget for conference and publication costs, an increase from thirty-nine to fifty in the staff, and the establishment of a medical care and group life insurance scheme for the staff. The financial statements, together with the reports of the Chairman of the Board of 'Trustees, the Treasurer and the Recording Secretary, are published in the January issue of the Transactions of the Academy $(25,265 ; 1963)$.

The Sciences, the new publication of the Academy, which was established in 1961, has been brought up to date on its publishing schedule. Thirty-one issues of the booklet, totalling 496 pages, were published during the year under review. In the Annals thirty-eight monographs, comprising 6,206 pages, and containing 501 papers by 796 authors, were published. As from January 1963, the publication date of any conference mono. graph will be within fourteen weeks subsequent to a conference, provided the authors submit their manuscripts within two weeks of the conference. Beginning with Volume 25, the Transactions will also follow this schedule. The demand for conferences to be held by the Academy continues to grow and the number of papers independently presented for publication in the Annals is also increasing regularly each year. Consequently, the Scientific Council has decided that with the current year, 1963, members of the Academy may select up to twenty separate monographs listed each year, with the added privilege of purchase of any publications of the Academy at a 20 per cent discount.

During the year, eighty-five meetings were held by the various sections and divisions of the Academy. The section of Biological and Medical Sciences held a joint meeting during January 1962 with the Columbia University seminar on "Genetics and Evolution" and a joint symposium with the division of Microbiology during April. The division of Instrumentation held a series of eight symposia on "Electronics in the Medical Specialities", and the papers in this series will be published shortly as a monograph. Details of the twenty-two conferences held between November 1961 and October 1962 are listed in the annual report.

The membership had a net increase of 622 during the year, with a record total of 16,249 members in October 1962. A maximum of fifty candidates may now be nominated each year to the fellowship of the Academy. The following were elected officers for 1963: C. H. Mushett, president, Rev. J. J. Lynch, president-elect, and K. Maramorosch and C. C. Stock, vice-presidents of the Scientific Council; C. R. Noback, recording secretary, and R, F. Nigrelli, corresponding secretary.

The Academy consists of the sections of biological and medical sciences, chemical sciences, physical sciences, and planetary sciences, and the divisions of anthropology, instrumentation, microbiology, psychology, biochemistry, biophysics, engineering and mathematics. The sections and divisions meet regularly, one evening a month, during the academic year, October-May, inclusive, in the Academy's premises in New York. The conferences are held at irregular intervals.

\section{UNIVERSITY EDUCATION IN INDIA}

\begin{abstract}
THE fourth annual Conference of Vice-Chancellors of the Indian universities and institutions 'deemed as universities' was held at New Delhi during October $11-13,1962$. The report of this Conference* includes the inaugural address of Dr. K. L. Shrimali, Minister of Education, Dr. D. S. Kothari's address on some aspects of university education, the address of the Prime Minister, Sri Jawaharlal Nehru, and the recommendations of the * India. University Grants Commission and Ministry of Education Vice-Chancellors' Conference, 1962. Pp. v+81. (New Delhi: University 0.72 dollars.
\end{abstract}

three Committees dealing with admissions, medium of instruction and related matters; service conditions of college and university teachers, and three-year degree courses; and contents of education and co-ordination of researeh. The most important feature of Dr. Shrimali's address is the stress laid on the medium of instruction. While any university or college will be completely free to continue to use English as a medium of instruction if it wishes, and use of English has been recommended as an alternative or associated medium by the National Integration Council, Dr. Shrimali is firmly convinced that unless 